\title{
Generation NeoTouch: how digital touch is impacting the way we are intimate
}

\section{Christine Würth}

,London, United Kingdom, hello@christinewurth.com

Published on 26 Mar 2020 | DOI: 10.14763/2020.1.1454

\begin{abstract}
The essay is written in the form of a magazine article published in 2039 - eleven years after the introduction of NeoTouch, a technology facilitating digital touch as human-to-human communication based on a brain-computer interface (BCI). The article follows Barbara, a young woman who recently had the technology deactivated, so as to understand the social and physical consequences of the device. Through the introduction of different voices the narrative integrates the history of the technology, the ethical, social and legal contexts and various personal accounts.
\end{abstract}

Keywords: Sci-fi, Haptic technology, Privacy, Brain-computer interface

\section{Article information}

Published: 26 Mar 2020

Licence: Creative Commons Attribution 3.0 Germany

Competing interests: The author has declared that no competing interests exist that have influenced the text.

URL: http://policyreview.info/essays/scifi/neotouch

Citation: Würth, C. (2020). Generation NeoTouch: how digital touch is impacting the way we are intimate. Internet Policy Review, 9(1). DOI: 10.14763/2020.1.1454

This essay is part of Science fiction and information law, a one-time special series of Internet Policy Review based on an essay competition guest-edited by Natali Helberger, Joost Poort, and Mykola Makhortykh.

Note: This is the plain text version of the essay. For the full artistic version (really worth it!), please download this PDF. 


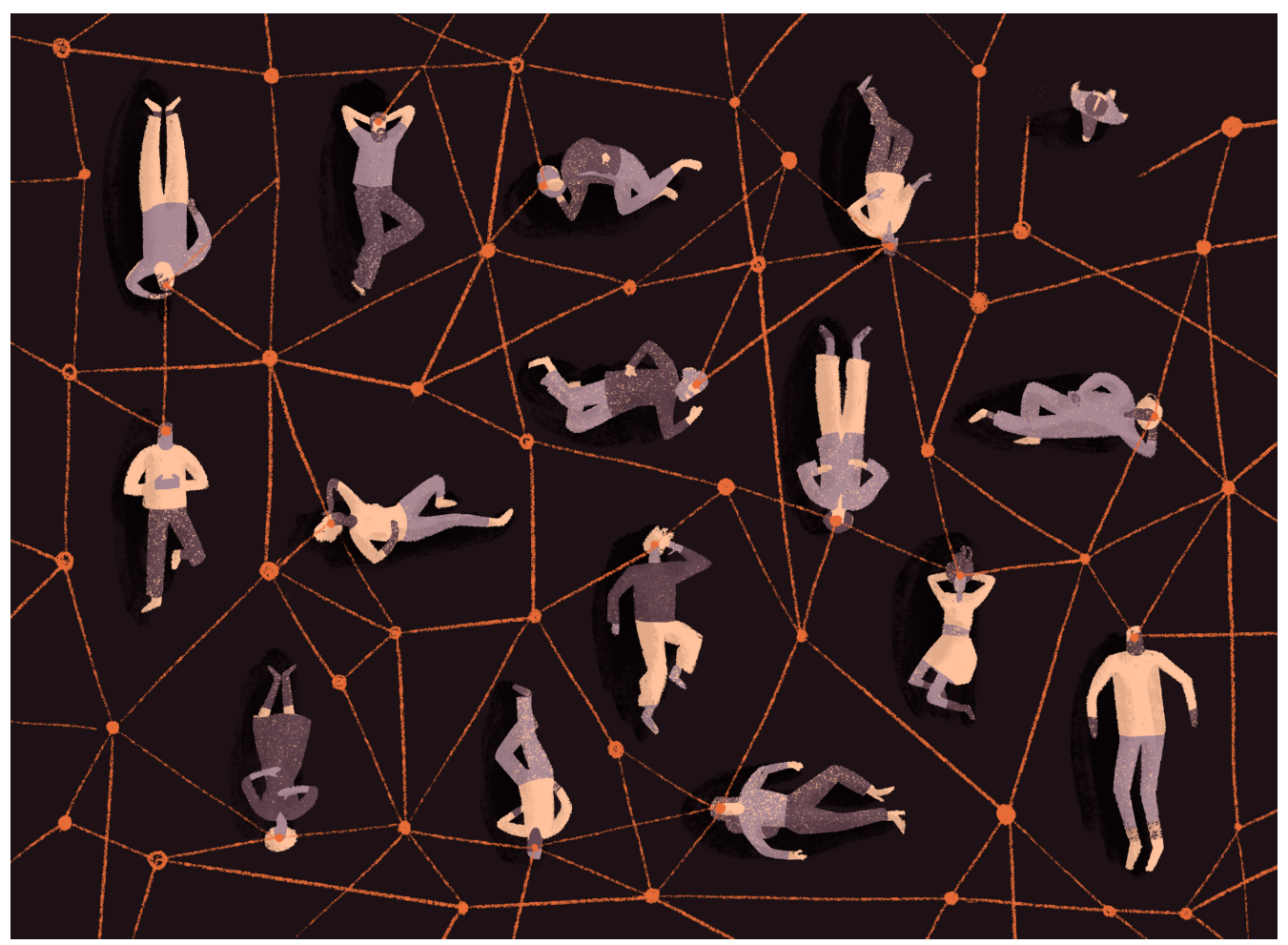

Illustration: Annika Huskamp

\section{TECH WEEKLY. Christine Wuerth. Sat 21 SEP 2039 14.0o BST.}

When Barbara Wells got her first NeoTouch, she was over the moon. As one of the last teenagers in her school to not have the BCI (brain-computer interface), she had been feeling left out. It had taken her months of arguing with her tech-critical parents to get their permission. For her sixteenth birthday, she finally got her wish. "I can't wait to finally experience digital touch," she said in her online diary at the time. Now, just two years later, she has had the interface permanently deactivated. For Barbara, the negative effects greatly outweighed the benefits.

At first, adopting haptic communication did exactly what she had hoped for. "Before, I just constantly had to admit to people that I didn't have it and explain why. It just made me feel really embarrassed. I mean, everyone else my age has it. People would be so surprised, and kind of suspicious. Like I was a weirdo.” With NeoTouch she finally felt part of her group, and more confident in making new friends and approaching boys.

Over the last decade, the adoption of NeoTouch has been fast and widespread, with an impressive $78 \%$ of teenagers between the age of 12 and 17 using it. (The age range in which it is legal to get the BCI set up, but only with parental approval). At this age, the tech is particularly common amongst girls. (This trend shows that, unfortunately, platonic touch is still far more common and accepted amongst girls than boys.)

This is a massive take-up in the eleven years since the technology first came to the market. But NeoTouch is not only popular amongst teenagers: the adoption rate has been surprising amongst all ages, most of all people in their $20 \mathrm{~s}$ and $30 \mathrm{~s}$.

Soon, however, Barbara felt the pressure of being 'always on' - this expectation to constantly being accessible to her friends, and her new boyfriend. "I don't think our brains are designed to always be connected to others," she says. "Even though in a way it really does feel the same as being touched, the other person isn't actually there. And somehow that contradiction really 
started to mess with my head."

Despite its undeniable success, NeoTouch has also prompted voices expressing concern. The last few years have seen an increase in people deactivating their devices and specialists questioning the effects of the technology on the users' privacy and physical integrity. But there are always those that oppose new technologies, so is NeoTouch really any different to other kinds of digital communication?

\section{A BRIEF HISTORY OF HAPTICS}

The arrival of NeoTouch on the market in 2028 redefined our understanding of haptic technology. Initially, the word haptics described the use of mechanical pressure, vibration, and motion to send impulses through the skin. Early attempts to incorporate touch into everyday technology like touch screens on portable devices were pretty basic by today's standards. Tactile interfaces developed in the 2010s were mainly used to navigate through information by touching the screen rather than touching anything beyond the screen. Now, haptic technology has evolved to the point that we cannot imagine daily activities like online shopping and watching films without a tactile dimension.

Early development of haptics saw competition from various fields. From gaming and VR to medicine, and from the automotive to the sex toy (or teledildonics) industry. While VR was making the headlines, it was, in fact, the sex industry that first came close to using haptics as an emotive interpersonal connection. Once the communication industry realised the potential that haptics held for a more emotive form of digital communication it started creating wearable devices incorporating vibration and muscle stimulation to express human touch. Smartphones had used vibrations as an alert mechanism for text messages and calls, but the new aim was to transform haptic input into a message in its own right.

The first Apple watch released in 2015, for example, was, in fact, introduced as the company's 'most personal device' ever: “... alerts aren't just immediate. They're intimate... We found a way to give technology a more human touch. Literally.'

If this doesn't show how much haptic tech has developed in the past few decades, what does!? At the same time, developments in neuroscience and nanotechnology made brain-computer interfaces more versatile and precise and the process of embedding them into the brain more routine and much less invasive. First just used for medical devices, they were soon commonplace in mainstream products for cognitive and physical enhancement.

Fast forward to 2029, when Somas Technologies introduced NeoTouch - the first technology to create a tactile sensation directly via the brain rather than on the surface of the skin. By approaching the challenge of haptic communication from this angle, they managed to completely revolutionise the industry.

Mike Seymour's new book "A new intimacy" investigates the rapid success of NeoTouch within the wider context of digital communication. "The height of globalisation, the "cult of the individual', and ever busier lives in the early 21st century meant that we spent less and less time with our loved ones and in face-to-face interactions in general," he writes. "It is no surprise that this coincided with the rise of digital communication and social media. After all, being lonely is literally unhealthy." 
But these technologies - he claims - could not compensate for the loss of real face-to-face interaction. "Even though we don't realise it, a major part of our communication is nonverbal, and the nature of digital, audio-visual communication means that most of that is lost. While we are not consciously aware of it, this still subconsciously diminishes the interaction. It's just less fulfilling, if we don't receive the same variety and density of cues."

This paved the way for haptics in an attempt to create more emotional connections. Digital communication collapses the sense of spatial distance. In the past, this has been done mainly using vision and sound. But the haptic revolution aimed to create a digital space that allows us to experience synthetic touch as an immersive experience, creating a real sense of physical closeness. The greatest potential was seen in the improvement of long-distance relationships and in offering health benefits for touch-deprived people such as the elderly and the sick. "The special thing about touch is that it's immediate and emotional. Being touched by someone makes us feel more connected to them." Seymour explains. "Touch is our 'private' sense and it has so many benefits for our health and relationships."

Despite the hype, early haptic devices were rather clunky and didn't really live up to the expectations of 'realistic' experiences that people had come to expect from image and soundbased communication. A range of devices in the 2010 s used localised vibration and muscle stimulation as symbolic messages of 'touch' to create a sense of physical presence. These novelty gadgets had very little use in everyday life. Later attempts relied on more and more advanced tech on or underneath the skin. However, this still confined the experience to specific parts of the body and was very limited in the quality and type of touch that could be conveyed.

\section{THE RISE OF NEOTOUCH}

In the late 2020 s bioelectronics finally left the lab and found their way into mainstream products for mental and physical health as well as cognitive improvement. These braincomputer interfaces also started being used to control devices remotely, directly through brain signals as well as to merge the human brain with artificial intelligence (AI). In the field of haptic technology, these interfaces made it possible to synthesise the experience of human touch without imitating it mechanically on the skin. Simply by stimulating the relevant brain areas directly, this new kind of haptic technology could create the physical illusion of touch in a very convincing way.

As Hannah Eisen, Designer at NeoTouch explained: "In the past technologists and scientists focused on simulating the physical process of touch. Obviously, they never got the technology to advance far enough to really create a realistic experience.

But then with the introduction of chip implants that interface directly with the brain came a massive shift in how we looked at the problem. Suddenly we were able to synthesise the holistic experience of touch instead of just recreating it mechanically." (NeoTouch. An IA Lab documentary, 2037) $\square$

As the first internal human-to-human interface, NeoTouch has - without a doubt - had the biggest impact on the nature of social interaction since the smartphone. In a video from 2028 that introduces the technology, the company claims: "NeoTouch lets you truly connect with another person at a distance. It enables instinctive, non-verbal communication through digital touch.” 
The video goes on to explain how it works: "The tactile interaction is received through your phone and then sent to the NeoTouch transducer: The Senser. This unit attaches to the skin behind the ear and communicates wirelessly with a network of nano-electronics in the brain to simulate the sensation of being in touch with another person. These neural implants serve as an internal brain-computer interface that controls and receives the communication. They interface directly with the somatosensory and motor cortex. It is the stimulation of these particular brain areas that allows us to create a realistic experience of touching and the sensation of being touched."

The Senser connects to the implants through ultrasound. Each chip is smaller than a grain of sand and can both pick up signals from the brain and send messages to the brain. That is how NeoTouch can send and receive the sensation of touch and create a natural interaction with another person. So how does it work?

The somatosensory cortex is a kind of map of our entire body. Stimulating targeted areas of this map can create a sense of touch anywhere on the skin. The motor cortex, on the other hand, controls the way we move and touch. Interfacing with these two brain areas means that NeoTouch can pick up our 'thoughts' of touching another person from our motor cortex and then send these impulses to recipient's somatosensory cortex to experience as touch.

"The interesting thing about the somatosensory cortex," says Seymour, "is the way in which it doesn't just process the objective quality of touch, it also does a kind of social and personal evaluation. That's why NeoTouch is able to give you a very individual experience with different people."

Stuart Johnson, CEO of Somas Technologies is quick to sell us NeoTouch as a valid replacement for real touch: $\square$ "For the first time we are able to artificially trigger our sense of intimacy and the feeling of physical presence."

Mike Seymour, however, is sceptical about whether synthetic touch can really deliver the same benefits as the real deal. "If someone touches me it's not just about the sensation of their hand touching me. It also depends on the way the rest of their body is positioned towards mine, the mood, and place... In a way, it's as if their whole body is touching mine. This element of touch is simply lacking in NeoTouch."

Barbara, too, was aware of that subtle but significant difference: "It feels the same, but something is off. Something is missing."

Touch is an element of nonverbal communication such as body language and eye contact. As such it is experienced and understood in the context of these other aspects of communication that combine into a complex, multi-sensory experience. This also means that it has unconscious effects on our emotions and behaviour towards others.

In this sense, touch is more than a sensation on the skin. We even speak of something being touching when it affects us emotionally. Connecting to another person through skin contact is deeply intuitive, emotive and full of meaning. Even before birth, we are connected to our mothers, and after birth touch is essential to growth, as well as physical and emotional development. To touch us, someone has to enter our private space. They have to literally be within arm's reach. Those we are comfortable being in such close proximity to are generally the people we are also emotionally close to. This makes the connection between touch and intimacy evident; the connection between emotional closeness and physical closeness. 
So what is the consequence of taking touch out of its natural context? How does it affect how we think of privacy and intimacy?

\section{THE MATTER OF PRIVACY}

The limitations of synthetic touch were not the only reason that ultimately made Barbara decide to get rid of her NeoTouch. "I felt trapped; like I could never really be alone," she admitted. "I mean, even before, I was constantly in contact with people through my phone. But the fact that it's in my head, that's just a different level, you know. It made me kind of paranoid.”

Barbara is not alone with these concerns. Privacy has become the main focus of discussion again in recent years, precisely because of BCIs such as NeoTouch. While many are surprised that anyone might still consider privacy of any importance, others wonder why we still need to fight for this right. Lawmakers should naturally respond to technological developments that move the goalposts of what data is 'private'.

"A main reason for the continuing debate is the question of how to define privacy," says lawyer and journalist Margot Bloom. "In the most basic sense, it can be defined as the control over aspects of our personal life such as our body, home, thoughts, and feelings, as well as our identity as a whole. It gives us the right to choose which of these 'private parts' of ourselves we allow others to access. In this way, the idea of personal privacy shaped the notion of data privacy."

Our relationship with privacy has continuously evolved throughout history in line with changing societal norms. Historically, the more people we are surrounded by and connected to, the more we rely on privacy to carve out a domain where we feel safe. But we also have an innate need for connection. Bloom links this to our origins as a tribal species. "Humans have a fundamental need to be social and close to others. We depend on each other for survival, so we physically and emotionally crave connections. We instinctively want others to know what we are thinking and doing, and we want to feel 'in touch'. That need is only heightened in a world where we are often spatially separated from our 'tribe'. As a consequence, we share our thoughts and our bodies online to feel connected. But simultaneously, we need a space to be ourselves, protected from the judgment of others, and have the freedom to express ourselves without the need to perform according to societal norms.”

Since the beginning of the digital age, however, we have been sold the idea of transparency as a means to national security while visibility is portrayed as a measure of popularity and success. Now, our private sphere is at stake more than ever. On one side, this is because of technologies like NeoTouch that keep us constantly linked to others. On the other, it is the access we give companies to our most private data - our thoughts, and feelings, our intimate interactions.

Psychologist and researcher Melanie McLeod has been very outspoken about the dilemma faced especially by young people in trying to find a healthy balance between their private and public selves. "When being seen or felt digitally is desirable, not just for the experience itself, but because it equates to being popular or successful, privacy in the form of anonymity becomes an obstacle. There is a societal expectation on how much we share of ourselves. Or more precisely, these societal norms affect how much we want to reveal and how much we feel comfortable revealing. This stands at odds with our natural need for privacy. So we perceive it as less relevant. This trade-off is known as the privacy paradox, and it completely undermines the 
concept of consent. Our desires are subconsciously used against us in such a way that we don't even want to say no anymore. We'd rather pay the price than feel alone."

Consequently, any demands for more privacy are so at odds with our present social norms that they don't find much support. The majority of us are now increasingly comfortable with exposing ourselves online. While the rest of us might still feel troubled about it, we are resigned to the fact that to function in our society we need to exist online. We are aware that any data collected and saved about us is a commodity to be traded and exploited.

To Bloom, the issue lies with people in power who look at privacy from a purely economic lens. "They just see the money they can make from your data. Privacy in any sense means a loss in profit. So they weaponise our need to share, to silently undermine our rights to privacy."

Every year more details are exposed on the kind of data that is collected and used to manipulate us without us giving explicit - or sometimes any - consent or even knowing about it. Bloom is currently leading the campaign 'Feel Safe' that aims to change regulations on how companies like Somas Technologies are allowed to use the data they collect from our brains. "I have been lobbying for stricter legislation for years. When it was leaked that Soma's Technologies had sold information of our interactions to health insurers, a line had been crossed, and I had to take action."

But how has NeoTouch ended up at the forefront of these debates?

McLeod explains how this has to do with the way NeoTouch merges our physical body and our data body in an unprecedented way. "Accepting that NeoTouch creates a felt presence of another person also means that that individual intrudes on my personal space and of course my body in a way that was impossible through messages and calls. The fact that I can physically experience an infringement on my digital self also makes any harassment or attack much more threatening. This makes NeoTouch a unique weapon for cyberbullying. And lastly, the fact that the interface has access to my brain completely exposes certain layers of my data, experience and even control over my physical body to external companies and anonymous individuals."

This gets us onto the threat of security breaches. Last year saw a wave of hacker attacks on the NeoTouch system. Even though it seems like Somas reacted quickly and there haven't been any issues since, the incident caused an uproar about the safety of the NeoTouch network, and many people decided to deactivate their devices.

I spoke to several victims of the breach about the emotional repercussions of what they experienced. Mun Wei Chan reported a haunting incident in which a hacker had intercepted the link between him and his husband Rick, who was away for work in Australia at the time. "I was oblivious to the imposter until I woke up one night from the feeling of hands wrapped around my neck." The experience has left its mark on Wei. Both he and his husband have since deactivated their devices and Wei has been seeing a therapist since the incident. He has also joined a larger group of victims in bringing a lawsuit against Somas Technologies for compensation.

\section{MODERN INTIMACY}

"We don't even have to go as far as anonymous hackers to seriously examine the question of who can touch whom," argues McLeod. "I'm even more worried about our general desensitisation 
towards personal boundaries when it comes to touch. The great ease NeoTouch created to access another's body seems to make people very blase about the impact of touch, and the value of intimacy. Young people don't learn to say no anymore. We don't know if it is the physical distance that dilutes the sense of agency over their own body or something else, but I'm worried about this development."

Barbara's story seems to validate McLeod's concerns. "Shortly after I got NeoTouch I started dating Aaron. He seemed to be a nice guy, but he would always expect me to have my NeoTouch connected to his. Not that I don't like that, but if I'm spending time with my friends or my parents it just feels wrong. And sometimes I just wanted time for myself. But he'd get really upset and annoyed and accused me of not wanting to be in the relationship. I felt like I had to be on NeoTouch to prove to him that I like him. When I ended up using NeoTouch less and less he started telling people at school that it's because I'm frigid.”

This hits a nerve on the ever-present (yet often ignored) question of gender in the design and experience of digital technology. There is a difference in the online behaviour that society allows and expects from men compared to women. This, of course, is nothing new. But the physical distance and anonymity online heighten the expression of these biases. Questions of safety for women online have been raised from the very beginning of digital life but have yet to be resolved successfully. Women are much more often victims of cyberbullying and particularly of sexually charged remarks and threats. They are expected to share pictures and give access to their bodies. Simultaneously their mere presence online is often taken as an invitation for objectification and even abuse. The physical nature of NeoTouch raised the stakes as it poses a real and immediate threat to women's bodies.

On a social level, NeoTouch has changed who we feel comfortable touching. A new study conducted by the British government Office for Science shows that we spend 50 minutes on average in digital touch interactions per day, compared to just 10 minutes of physical touch. This might make us worry about digital touch replacing physical closeness, but at the same time, this is a vast increase in our openness to tactile interactions as a whole. The mere number of people we would be happy to touch has increased dramatically since the adoption of the technology. These are mainly people in our social circle; online and offline. In the same study, people reported having developed a stronger physical bond with family members. And, just as specialists had predicted, the most positive feedback has been from people in long-distance relationships.

Samantha Fry and Jacob Lundt have been living in different countries for the last three years and love the way NeoTouch has enabled them to keep up a physical relationship despite the distance. "We actually didn't have NeoTouch before. We got it specifically for this time apart and don't use it to interact with anyone else," explains Jacob. Both of them are aware of the pitfalls of digital life and weighed up all their options before giving NeoTouch a go. "I think, like with everything else, you need to have a healthy reflected relationship to technology. Especially if this tech facilitates your human relationships. I see how this can be challenging for people.”

Despite this, they both agree that NeoTouch has been an invaluable asset to their relationship during this time apart. "It's not just about sexual intimacy," assures Samantha, "it's about all those little everyday interactions through which you show your affection and attention. Stroking your partner's arm or hair, hugging, falling asleep together... Honestly, if we didn't have this, I'm not sure our relationship would have survived the last three years.”

McLeod, however, is concerned about relationships where digital touch is being used not to 
bridge a distance but to create one: "NeoTouch changed the expectation of emotional and physical availability. Even sexual availability. At the same time, it shields us from real intimacy. This creates a strange paradox. We don't recognise how lonely we are, nor how we've slowly lost agency of our own body - the physical, emotional and digital."

Seymout warns that spending time in digital interactions to avoid real-world problems might only intensify these issues. "It is the same for haptic technology as for any other kind of digital communication. People don't get to practice basic non-verbal communication, so they are bad at it and then more insecure about interacting in person. This is most prominent in young people. Lacking these skills makes it harder to empathise, and to be truly connected. We settle for digital touch which cannot replace true intimacy. I'm really worried about how this is changing the perception and value of intimacy. Where our society was suffering from a hyper-vigilance of personal boundaries only 20 years ago, these boundaries seem to have all but disappeared now, and touch has become superfluous and banal. Some see these numbers of increased intimacy through NeoTouch as a positive result, but I'm more concerned that this is actually a symptom of the way we devalue touch through this lesser, more casual substitute. This could be affecting the way we value intimacy as a whole. If I don't care who has access to my data and my body, how can I ever truly feel close to someone?"

McLeod spoke about the effect this has on the development of teenagers in an earlier interview: "I'm actively supporting the efforts to raise the age restriction on NeoTouch. We are already seeing a shift in behaviour in the younger generation. I'm sure we all remember how difficult and awkward it is to be a teenager. To have to deal with this new body and all these hormones and figure out how to be intimate with others. But to sidestep that development by interacting only through digital touch, at a so-called 'safe distance' is creating so many problems. Teenagers are not learning to emotionally connect, let alone to understand their own boundaries and needs, and those of others.” $\square$ (NeoTouch. An IA Lab documentary, 2037) $\square$

\section{ALONE TOGETHER}

She is also interested in the connection between digital intimacy and loneliness. "In modern times - and especially in urban life - we retreat into our homes, and capsule ourselves off from other people. As a result, we feel more lonely and create evermore technologies to connect ourselves to others in increasingly immersive, realistic ways. In return, the fact that these connections happen in a digital space means we have fewer incentives to seek out physical spaces to connect."

If we do leave our homes, many of our interactions still happen via digital channels and remove us emotionally from our physical environments and interactions. Even when out with friends, we are still connected to various devices, always aware of potential interactions waiting for us online. Can we really say we are fully present? This kind of multitasking created by technology keeps our attention constantly split between real-life interactions and digital ones.

We are in touch with someone digitally but often simultaneously continue with our real-life activities, only partly paying attention to the digital experience. This seriously affects how much we connect to the person at the other end and how much we can 'profit' from the connection.

Bloom insists that there is no way to truly avoid the influence technology has on human interactions. "We need to educate young people, not just in digital literacy but also in a new 
literacy that bridges the digital and the physical. And beyond that, we need to have more of a debate around the social and ethical implications. After all, changes in mindsets of the individual result in changes in society as a whole and therefore concern all of us, irrespective of age."

But what scale of data breach would we need to understand the severity of the threat? What scientific findings will make us sit up and pay attention to the possible dangers of technologies like NeoTouch?

Research into the effects, whether positive or negative, have so far been inconclusive. The consequences can be observed in so many different aspects of life that it is difficult to see the bigger picture. It is hard to show the exact correlation of changes in phenomena spanning from empathy and understanding, to our sense of identity and willingness to take risk.

In the meantime Barbara is happy and certain about her decision to have NeoTouch deactivated. "I guess I had to find out for myself what it is like and it was kind of hard to ultimately have it switched off. A lot of my friends don't understand my decision. The first few days after, I felt kind of isolated. But more than that it was just a relief. And now I don't miss it at all." She does however think, that it did make her more aware of touch. "I'm more strict with who I let touch me, yes. But I think I'm actually more physical with my family now. My close friends, too. I hope that maybe they'll slowly realise how much better the real thing is." 